\title{
The Effects of Mantra Meditation on Self-compassion and Stress of Office Workers
}

\author{
Heesook Kwon1), Meesook Cheong2)
}

\begin{abstract}
High job-stress is more than 2 times likely to cause depression, anxiety, and stress symptoms. More 70\% of professional managers responded that they felt stressed in their workplaces for the past 10 years. This study investigates the effects of mantra meditation on self-compassion and stress of office workers. The subjects of this study were 20 head managers of apartments in $\mathrm{K}$ city. The purpose of this study is to help office workers recognize and accept negative emotions they experienced and to guide them to pleasantly work. The results of the study revealed that first, a t-value of the paired samples test of self-compassion was 9.560 and a significant probability was .000 . Therefore, it can be judged that the mantra meditation is effective in improving self-compassion (awareness index). Second, it was found that the $\mathrm{t}$-value of the paired samples test of the stress index was 4.684 and the significant probability was .000 . Therefore, it can be judged that mantra meditation is effective in minimizing stress. In conclusion, it is found that the mantra meditation can help office workers to recognize and accept their current state, and to achieve a happy work-life. But it is unable to generalize the results because this program ran for office workers who have the same job in one city. Therefore, it is necessary to implement this program for office workers who have different jobs in various cities. Also, mantra meditation is still unfamiliar to the general public, so efforts are needed to popularize it.
\end{abstract}

Keywords: Mantra, Meditation, Self-Compassion, Stress, Office workers

\section{Introduction}

The 2017 Work Environment Survey conducted by the Korea Occupational Safety and Health Agency (KOSHA) revealed that $35.2 \%$ of respondents including managers answered "more than usually" to the question "Are you usually stressed at work?" This response rate was highest in the job category. Among the "sometimes" responses, 84.3\% were managers, ranking 2nd after soldiers (92.3\%). Looking at the biennial 'social survey: the degree of stress' conducted by the Statistics of Korea since 2008, more than $70 \%$ of professional managers felt stressed in their

Received(October 28, 2019), Review Result(1st: November 21, 2019, 2nd: December 31, 2019), Accepted(March 25, 2020)

1) (Student) 02838 Dept. Naturopathy, DongBang Culture Univ., Seongbook-dong, Seongbook-gu, Seoul, Korea email: na01982@hanmail.net

2) (Professor, Corresponding Author) 02838 Dept. Naturopathy, DongBang Culture Univ., Seongbook-dong, Seongbook-gu, Seoul, Korea

email: ayurveda16@naver.com 
workplaces $(72.9 \% \sim 79.5 \%)$. Since stress can be induced in all human organizational life, it is recognized that stress is inevitable even though there are individual differences (Lee Soon-hee, 1991)[1]. Even so, high stress threatens mental health, and furthermore human life. Park Kyu-cheol et. al(2008) found that high job stress is 4.93 times likely to cause depression, 2.70 times towards anxiety, and 3.53 times to stress symptoms[2]. Knowing these risks of stress, the Ministry of Employment and Labor has provided free Employee Assistance Program(EAP) counseling services since 2009. These services help workers solve their job-stress, depression and so on.

Recently, various studies on how to cope with stress have been actively conducted including a study on self-compassion. Self-compassion is a 'healthy form of self-acceptance that takes a warm attitude, even if you are not happy with yourself and the environment around you (Neff, 2003)[3].' There are many previous studies on self-compassion in Korea. Ko Eun-ju (2013)[4] revealed that self-compassion can grow happiness of middle school students by improving self-efficacy and psychological well-being. Kim Ji-woo (2015)[5] found that self-compassion contributed to the increase of feelings of well-being by reducing negative emotions among high school girls and promoting their positive emotions. Kim Jong-eun (2016)[6], who studied female college students, showed that self-esteem was enhanced by increasing self-acceptance and positive emotions through self-compassion. Choi So-yang (2017)[7], studied menopausal women and found that rising positive emotions reduced depression and stress. Lee Woon (2016)[8] found that promoting self-compassion of adults had a positive effect on improving happiness. Yu Yeon-hwa (2010)[9] found that even after controlling the effects of life stress on psychological symptoms, self-compassion contributed significantly to the reduction of overall psychological symptom levels including anxiety symptoms and stress symptoms.

Another study of ways to deal with stress is to study about mantra meditation. Mantra feels vibrations and waves using the power of sound. It is a sensory tool that can heal the mind by connecting feeling with meaning. Mantra is a combination of sacred syllables that form the core of spiritual energy (Cheong Mee-sook, 2015)[10]. Mantra is a language that generates changes and transformations by the wavelength of the healing sound that occurs when repeatedly making a sound (Cheong Mee-sook, 2017)[11]. Mantra is part of Ashtanga Yoga Phase 5 and is one of the ways to get easily into meditation (Dyana) by increasing concentration. Mantra means saving one's painful mind. Om mantra is effective in creating healing spaces; Hum mantra dissolves negative energy, and; Ram mantra is used to bring divine light and cosmic energy into the treatment room (Cheong Mee-sook, 2017)[11].

Looking at the previous studies, Hwang Yeon-ah (2005)[12] found that mantra had a positive 
effect on reducing the stress of elementary school students. Lee Kyung-sook (2008)[13], Lee Deok-yi (2006)[14], and Kim Eun-su(2005)[15] revealed that mantra was effective in mitigating aggression and impulsiveness of middle school students. Jeong Sun-hwa (2007)[16] said that mantra helped to improve the self-esteem of high school students. In addition, Jang Mi-yeon (2006)[17] found that mantra reduced the aggression and impulsiveness of sexual assault offenders. Kim Eun-sun (2014)[18] found that mantra was effective in the mental and physical stability of college students. Yeo Cheong-ja (2014)[19] found that mantra was effective in reducing stress. Also, Do Sung-sook (2012)[20] revealed that mantra was effective in reducing depression and anxiety among middle-aged women. Kim Jae-ok (2016)[21] showed that mantra made elderly people with depression and loneliness to feel psychological well-being by increasing positive emotions and decreasing negative emotions.

Various studies have been conducted on the effect of stress reduction through mantra meditation and self-compassion. Therefore, this study focused on whether the cause of stress reduction effect through mantra meditation was related to the improvement of self-compassion through mantra meditation. In other words, this study studied first, whether mantra meditation reduced stress. And then, this study investigated whether the reason that reduced stress was related to improving self-compassion through mantra.

This study is aimed at the head of apartment managers whose duties are to manage the apartments and to solve the complaints of the residents. Each head of managers takes care of an average of 350 households with many different and complicated complaints. Some of them are the same repetitive complaints and malicious complaints that arise because the requirements of the petitioners are not met. In the process of responding to the petitioners that raised malicious complaints, the head of managers is exposed to psychological and emotional stresses such as tension and anxiety. Failure to resolve these stresses in a timely manner can lead to depression and lethargy.

The purpose of this study is to help workers to reduce stress using the mantra. Mantra meditation can raise self-compassion which is a healthy way for workers to accept their stressful situations, and consequently to help them reduce stress. This study aims to guide the workers who are exposed to various stresses to use meditation to correct the mental imbalance caused by stress and achieve psychological peace.

\section{Methods of Study}

\subsection{Subject}


This study was conducted among the head of apartment managers in $\mathrm{K}$ city. A total of 20 subjects consisted of 8 females and 12 males, who gave their consent to use their data in the study. Females consisted of three-person in their late 40s, four in early 50s, and one in late 50s. Males consisted of one person in his early 50s, six in late 50s, three in early 60s, and two in late 60s. All 20 subjects graduated from university and are married.

Twenty people were recruited to run the program. There were 23 applicants, but three of them were out of this study for the reason that the individual's condition or purpose was not appropriate for this study. The two were not suitable as subjects for this study, because they were suspected a serious mental illness after the interview and urgently needed psychiatric counseling rather than this program. The other one complained of extreme fear and dizziness during the program, and then voluntarily received psychiatric medication to drop out. Therefore, this study was conducted with the remaining 20 people.

\subsection{Design of Study}

The study was conducted from June 1, 2019 to December 20, 2019. In June, the researchers collected data, set up a program, and selected participants for this study. The study program ran from July 1, 2019, to November 30, 2019, once a week, every Monday from seven to nine in the evening, with a total of 12 sessions. During the initial 4 sessions, subjects learned and practiced mantra meditation. The next stages (5th to 8th sessions) are the healing stages, in which subjects started healing himself/herself through mantra meditation. The last stages (9th to 12th sessions) are the stage of healing and spiritual growth. In advance, the participants were interviewed to agree on the purpose, content, and duration of the program.

The program contents are as follows. In the 1st session, the program was explained in general, and the subjects did a pre-test on the stress response inventory and self-compassion scale, along with self-introduction. In the 2nd session, the concepts, methods, and effects of meditation were explained. The subjects learned how to meditate to suit themselves. In the 3rd and 4th sessions, they learned how to combine mantra and breathing to change their mind's energy and practiced it. In the 5th and 6th sessions, they relaxed their nervous body and mind due to stress by using Om mantra meditation. In the 7th and 8th sessions, they practiced Hum mantra meditation, which is used to dissolve negative energy in the body and mind, restore nerve function, and improve expression. In the 9th and 10th sessions, they meditated using Om mantra and Hum mantra, along with Sam mantra, which relieved their mental anxiety. In the 11th session, they noticed the change of body and mind through mantra meditation and shared 
the feelings, changes, and spiritual growth that they have made after meditation. In the last session, they did a post-test on the stress response inventory and self-compassion scale.

\subsection{Measurement Tool}

The stress response inventory, developed by Koh Kyung-bong et al.(2000)[22], consists of seven subscales : tension, aggression, somatization, anger, depression, fatigue, and frustration. In detail, this inventory is a total of 39 questions, which includes six questions on tension, four on aggression, three on somatization, six on anger, eight on depression, five on fatigue, and seven on frustration. In this study, all questions answered were reported as stress response, and were used for data analysis. This inventory also used the five-point Likert-scale where 1 means 'not at all' and 5 means 'very much' indicating that the higher the score, the more responsive to stress.

The self-compassion scale and stress response inventory were used as measurement tools. The self-compassion scale used the self-report questionnaire of Kim Kyeong-eui et. al(2008)[23]. The statement of self-compassion consists of six factors: Self-Kindness, Self-Judgement, Common Humanity, Isolation, Mindfulness, and Over-identified. It has a total of 26 questions. Specifically, this scale includes five questions on self-kindness $(5,12,19,23,26)$, five on self-judgement $(1,8,11,16,21)$, four on common humanity $(3,7,10,15)$, four on isolation $(9,14,17,22)$, and four on over-identified $(2,6,20,24)$. This use the five-point Likert-scale where 1 means 'not at all', 2 for 'not normally', 3 for 'normal', 4 for 'usually', and 5 for 'always'.

\subsection{Data Analysis}

SPSS 24 was used for data analysis. T-test was used to examine the pre- and post- test results of the mantra meditation program.

\section{Results}

This study used scale tests and t-tests to analyze data gathered from the respondents before and after the mantra meditation program. First, the paired samples statistics of the stress response inventory are shown in [Table 1]. 
The Effects of Mantra Meditation on Self-compassion and Stress of Office Workers

[Table 1] Paired Samples Statistics of the Stress Response Inventory

\begin{tabular}{cccccc}
\hline & & Mean & N & Std. Deviation & Std. Error Mean \\
\hline \multirow{2}{*}{ Pair 1} & Pre & 86.700 & 20 & 29.4102 & 6.5763 \\
\cline { 2 - 6 } & Post & 74.850 & 20 & 25.6172 & 5.7282 \\
\hline
\end{tabular}

As a result of analyzing paired samples statistics with a sample of stress response inventory of 20 , the stress index resulted to 86.700 at pre-test and 74.850 at post-test. In other words, the stress index reduced 11.85 through the mantra meditation program.

The paired samples correlations of the stress response inventory can be found in [Table 2].

[Table 2] Paired Samples correlations of the Stress Response Inventory

\begin{tabular}{cccc}
\hline Pair 1 & N & Correlation & Sig. \\
\hline Pre \& Post & 20 & .925 & .000 \\
\hline
\end{tabular}

Paired samples correlation coefficient of the stress response inventory shows a correlation with stress index before and after the mantra meditation program. Two stress indexes had similarities of $92.5 \%$, with a significant probability of .000 . Therefore, it can be said that there is a significant correlation.

The paired samples test of stress response inventory can be seen in [Table 3] below.

[Table 3] Paired Samples Test of Stress Response Inventory

\begin{tabular}{|c|c|c|c|c|c|c|c|c|}
\hline \multirow{3}{*}{ Pair 1} & \multicolumn{5}{|c|}{ Paired Differences } & \multirow{3}{*}{$\mathrm{t}$} & \multirow{3}{*}{$\mathrm{df}$} & \multirow{3}{*}{$\begin{array}{c}\text { Sig. } \\
\text { (2-tailed) }\end{array}$} \\
\hline & \multirow[t]{2}{*}{ Mean } & \multirow[t]{2}{*}{$\begin{array}{c}\text { Std. } \\
\text { Deviation }\end{array}$} & \multirow{2}{*}{$\begin{array}{l}\text { Std. } \\
\text { Error } \\
\text { Mean }\end{array}$} & \multicolumn{2}{|c|}{$\begin{array}{l}95 \% \text { Confidence } \\
\text { Interval of the } \\
\text { Difference }\end{array}$} & & & \\
\hline & & & & Lower & Upper & & & \\
\hline Pre-Post & 11.8500 & 11.3150 & 2.5301 & 6.5544 & 17.1456 & 4.684 & 19 & .000 \\
\hline
\end{tabular}

The $t$-value of the paired samples test on the stress response inventory was 4.684, and the significance probability was .000 . Since the $t$-value is greater than 3.30 and the significance probability is smaller than the significance level of .05, the difference between the stress response inventory before and after the meditation program is statistically significant. Therefore, the null hypothesis was rejected, and the alternative hypothesis was adopted. In other words, 
the results of this study suggest that the mantra meditation program is effective in reducing the stress index.

The analysis results of self-compassion scale are as follows. The paired sample statistic of self-compassion scale is shown in [Table 4] below.

[Table 4] Paired Samples Statistics of the Self-compassion Scale

\begin{tabular}{cccccc}
\hline & & Mean & N & Std. Deviation & Std. Error Mean \\
\hline \multirow{2}{*}{ pair 1} & Post- & 70.000 & 20 & 9.4256 & 2.1076 \\
\cline { 2 - 6 } & Pre- & 60.750 & 20 & 8.9376 & 1.9985 \\
\hline
\end{tabular}

As a result of analyzing paired samples statistics with a sample of self-compassion scale of 20, the self-compassion awareness index resulted to 60.750 at pre-test and 70.0 at post-test. In other words, the awareness index improved 9.25 through the mantra meditation program.

The paired samples correlations of the self-compassion scale can be found in [Table 5].

[Table 5] Paired Samples Correlations of the Self-compassion Scale

\begin{tabular}{ccccc}
\hline & & $\mathrm{N}$ & Correlation & Sig. \\
\hline \multirow{2}{*}{ Pair 1} & Post \& Pre & 20 & .890 & .000 \\
\hline
\end{tabular}

Paired samples correlation coefficient of the self-compassion scale shows a correlation with the self-compassion awareness index before and after the mantra meditation program. Two awareness indexes had similarities of $89 \%$, with a significant probability of .000 . Therefore, it can be said that there is a significant correlation.

The paired samples test of the self-compassion can be seen in [Table 6] below.

[Table 6] Paired Samples Test of the Self-compassion Scale

\begin{tabular}{|c|c|c|c|c|c|c|c|c|}
\hline \multirow{3}{*}{ Pair 1} & \multicolumn{5}{|c|}{ Paired Differences } & \multirow{3}{*}{$\mathrm{t}$} & \multirow{3}{*}{$\mathrm{df}$} & \multirow{3}{*}{$\begin{array}{c}\text { Sig. } \\
\text { (2-tailed) }\end{array}$} \\
\hline & \multirow[t]{2}{*}{ Mean } & \multirow[t]{2}{*}{$\begin{array}{c}\text { Std. } \\
\text { Deviation }\end{array}$} & \multirow{2}{*}{$\begin{array}{l}\text { Std. } \\
\text { Error } \\
\text { Mean }\end{array}$} & \multicolumn{2}{|c|}{$\begin{array}{l}\text { 95\% Confidence } \\
\text { Interval of the } \\
\text { Difference }\end{array}$} & & & \\
\hline & & & & Lower & Upper & & & \\
\hline Post-Pre & 9.2500 & 4.3271 & .9676 & 7.2249 & 11.2751 & 9.560 & 19 & .000 \\
\hline
\end{tabular}

$\mathrm{t} \geq 3.30,{ }^{* * *} \mathrm{p}<0.001, \mathrm{df}: \mathrm{N}-1$ 
The $t$-value of the paired samples test on the self-compassion scale was 9.560, and the significance probability was .000 . Since the $t$-value is greater than 3.30 and the significance probability is smaller than the significance level of .05 , the difference between the self-compassion scale before and after the meditation program is statistically significant. Therefore, the null hypothesis was rejected, and alternative hypothesis was adopted. In other words, the results of this study suggest that the mantra meditation program is effective in improving self-compassion (awareness index).

\section{Conclusion}

This study aims to investigate the effects of mantra meditation on self-compassion and stress of office workers. The study was conducted 20 head of apartment managers in $\mathrm{K}$ city. The purpose of this study is to guide office workers to observe themselves, to recognize heir negative emotions and to consequently understand, accept, love themselves, and to live happily.

The results of this study are as follows. First, as a result of analyzing the subjects' stress response inventory, the $t$-value of paired samples test of the stress response inventory was 4.684, and if the t-value is greater than 3.30, it can be judged to be significant. Since the probability of significance was .000, which is smaller than the significance level of .05 , the difference of the stress response inventory before and after the mantra meditation program is found to be statistically significant. Therefore, the null hypothesis was rejected, and the alternative hypothesis was adopted. In other words, the mantra meditation program can be judged to be effective in reducing stress. This result is consistent with the study of Hwang Yeon-ah (2005)[12] and Yeo Cheong-ja (2014)[19].

Second, as a result of analyzing the subjects' self-compassion scale, the t-value of paired samples test of the self-compassion scale was 9.560. The probability of significance was .000, which is smaller than the significance level of .05 , so the difference in the self-compassion scale before and after the mantra meditation program is statistically significant. Therefore, the null hypothesis was rejected, and the alternative hypothesis was adopted. It means that the mantra meditation program can be judged to be effective in improving self-compassion (awareness index). In other words, it can be concluded that mantra meditation improved self-compassion and that enhanced self-compassion helped reduce stress like the results of Ko Eun-ju (2013)[4], Kim Ji-woo (2015)[5], and Lee Woon (2016)[8].

The limitation of this study is that it is unable to generalize the results because this program ran for office workers who have the same job in one city. Therefore, it is necessary to 
implement this program for office workers who have different jobs in various cities to derive more reliable results. This study suggests the following. First, since this study is quantitative, it is good to do qualitative research to hear the voices of the subjects one by one. Second, mantra meditation is still unfamiliar to the general public, so efforts are needed to popularize it. To this end, it is necessary to create an opportunity for people to experience the mantra meditation program and to create a space and program for continuous participation. With more studies on mantra meditation and popularization of this practice, the study hoped that many office workers will realize their current state, improve their loving-kindness and compassion, and achieve a happy work-life through mantra meditation.

\section{References}

[1] S. H. Lee, Study on Teacher's Stress: Prevalence and sources, Kyungsung University, Master's Thesis, (1991)

[2] K. C. Park, G. J. Lee, J. B. Park, G. B. Min, G. W. Lee, Association between Occupational Stress and Depression, Anxiety, and Stress Symptoms among White-collar Male Workers in an Automotive Company, Annals of Occupational and Environmental Medicine, (008), Vol.20, No.3, pp.215-224, DOI: 10.35371/kjoem.2008.20.3.215

[3] K. Neff, Self-compassion: An alternative conceptualization of a healthy attitude toward oneself, Self and Identity, (2003), Vol.2, No.2 pp.85-101, DOI: 10.1080/15298860309032

[4] E. J. Ko, The Effects of mindful loving-kindness meditation on student's self-compassion, self-efficacy and psychological well-being, Sungkyunkwan University, Master's Thesis, (2014)

[5] J. W. Kim, Effects of The K-MBSR on well-being and self-compassion of female high school students, Sunchon National University, Master's Thesis, (2015)

[6] J. E. Kim, The Effect of mindful self-compassion on the negative body image of female university students, Duksung Women's University, Master's Thesis, (2016)

[7] S. Y. Choi, The Effect of Self-Compassion Meditation on Depression and Stress in Climacteric Women, Duksung Women's University, Master's Thesis, (2017)

[8] W. Lee, A study on the effect of Loving-Kindness meditation group counseling to the promotion of adults' happiness, Dongguk University, Master's Thesis, (2016)

[9] Y. H. Yu, S. H. Lee, Y. R. Jo, The relationships between self-compassion, life stress, social support, and psychological symptoms, Cognitive Behavior Therapy in Korea, (2010), Vol.10, No.2, pp.43-59, UCI: G704-SER000008935.2010.10.2.005

[10] M. S. Cheong, Theory and Practice of Ayurveda, Yeorae Publishers, (2017), pp.414-428.

[11] M. S. Cheong, A study on correlation between the mantra of Buddhism and mantras of ayurveda, Korean 
Journal of Ayurveda, (2015), Vo1.3. No.1, pp.82-102.

[12] Y. A. Hwang, The Effects of Gayatri Mantra on Elementary School Students' Stress, Changwon National University, Master's Thesis, (2005)

[13] K. S. Lee, The Effects of on Om Aim Mantra on the Attentions of Pita Constitution of Middle School Students, Changwon National University, Master's Thesis, (2008)

[14] D. Y. Lee, The Influences of Mantra Meditation on Mitigation of Middle School Student' Aggression, Changwon National University, Master's Thesis, (2006)

[15] E. S. Kim, The Effects of Mantra Meditation on Mitigation of Middle School Students' Impulsiveness, Changwon National University, Master's Thesis, (2005)

[16] S. H. Jeong, The Effect of Mantra Maditation Program on high School Girls' Self-Esteem, Changwon National University, Master's Thesis, (2006)

[17] M. Y. Jang, A Effect of mantra maditation Program to an agressivenessand impulsiveness of sexual violence agent, Changwon National University, Master's Thesis, (2006)

[18] E. S. Kim, The Effects of mantra meditation on the body and mind of college students, Changwon National University, Doctor's Thesis, (2014)

[19] C. J. Yeo, The effect of mantra meditation program on teachers' stress and psychological well-being, The Korean East West Mind Science, (2014), Vol.17, No.1, pp.61-75.

[20] S. S. Do, The Effects of a Chakra Mantra Meditation Program on the Reduction of Depression \& Anxiety of Middle-Aged Women, Changwon National University, Master's Thesis, (2012)

[21] J. O. Kim, The Effects of Ayurveda Mantra on the Physical Changes of the Elderly, Korean Journal of Ayurveda, (2016), Vol.4, No.1, pp.35-48.

[22] K. B. Koh, J. G. Park, C. H. Kim, Development of the Stress Response Inventory, Journal of the Korean Neuropsychiatric Association, (2000), Vol.39, No.4, pp.707-719.

[23] K. E. Kim, G. D. Yi, Y. R. Cho, S. H. Chai, W. K. Lee, The validation study of the Korean version of the Self-Compassion Scale, The Korean Journal of Health Psychology, (2008), Vol.13, No.4, pp.1023-1044, DOI: $10.17315 / \mathrm{kjhp} .2008 .13 .4 .012$ 